\section{A radiodifusão no Uruguai e o debate da democratização da comunicação: o que muda com a nova lei $\mathbf{n}^{-}$ 19.307? \\ [Broadcasting in Uruguay and the democratisation of communication debate: what changes with the new law 19.307?]}

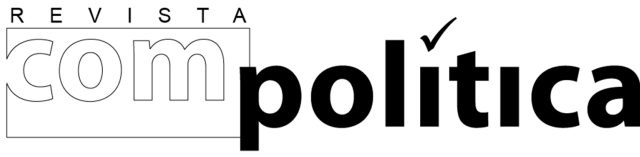

revista compolítica 2016, vol. 6(1)

compolitica.org/revista

ISSN: 2236-4781 DOI: 10.21878/compolitica.2016.6.1.227

\section{Chalini Torquato Barros}

Universidade Federal do Rio de Janeiro

[Federal University of Rio de Janeiro]

\title{
Resumo
}

O presente artigo busca oferecer uma aproximação comparativa entre a nova lei de meios uruguaia, $n^{\circ}$ 19.307, e a legislação que anteriormente vigorava sobre o setor de radiodifusão. Para isso, será utilizado o método comparativo, a partir da aplicação de categorias de indicadores, já utilizado em pesquisa anterior. Tem-se como pano de fundo o debate acerca da democratização da comunicação enquanto proposta política para o setor de mídia, partindo de um levantamento histórico e um referencial teórico que dialoga com contribuições da Teoria Democrática e da Economia Política da Comunicação. Conclui-se que a nova lei traz um avanço fundamental para o debate uruguaio sobre um modelo mais democrático de mídia.

Palavras-chave: radiodifusão; legislação; Uruguai.

\begin{abstract}
This paper tries to establish a comparative approach between the new law of Uruguayan media, No. 19,307 and the legislation that previously prevailed on the broadcasting industry. For this, we will use the comparative method, from the application of indicators of categories already used in previous research. The background is the debate on the democratization of communication as proposed policy for the media sector, based on a theoretical framework that dialogues with contributions of the Democratic Theory and the Economics of Political Communication. We conclude that the new law brings a fundamental advance for Uruguayan debate on a more democratic model of media.
\end{abstract}

Keywords: broadcasting; legislation; Uruguay. 


\section{A radiodifusão no Uruguai e o debate da democratização da comunicação: o que muda com a nova lei $n^{\circ} 19.307$ ?}

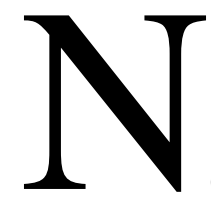

a América Latina, o resultado histórico de leis permissivas e imprecisas, (agravado com a assimilação de princípios neoliberais, notadamente na década de 1990) foi a consolidação de mercados audiovisuais e de informação concentrados e excludentes. Gradativamente, contudo, o fortalecimento dos clamores pelo direito à comunicação têm encontrado canalização em reformulações regulatórias que, em diferentes medidas, reestruturam o setor e aparentam oferecer maior porosidade institucional a essas demandas, sendo assim identificadas muitas vezes como uma democratização do setor de mídia ${ }^{1}$.

O Uruguai, que já se destacava nos debates regulatórios da América Latina por ter aprovado uma lei para a radiodifusão comunitária em 2007 que se tornou referência, volta a ganhar atenção com a aprovação em dezembro de 2014 da lei no 19.307 - cujo processo possui a particularidade de ter sido protagonizado pela iniciativa da sociedade civil. O país apresentava anteriormente uma legislação dispersa e fragmentada e tinha a permissividade como sua maior fragilidade, mas agora assiste a reestruturações consideráveis para o setor com a nova "Lei de Serviços de Comunicação Audiovisual" como o impedimento a monopólios e oligopólios, o fomento à produção nacional, a regulação de conteúdo e a reformulação do desenho institucional das autoridades reguladoras.

O presente artigo se propõe a estabelecer uma aproximação comparativa entre essa nova legislação e a que abarcava o setor de radiodifusão uruguaio. Para isso, será utilizado o método de categorias de indicadores aplicado em pesquisa anterior e desenvolvido especificamente para o estudo comparativo em cenários de media policy ${ }^{2}$. Tal método se sustentará na análise documental, tendo como corpus as leis e regulamentos principais para o setor uruguaio de radiodifusão. 
Em um primeiro momento, o texto traz a apresentação do setor uruguaio de radiodifusão, mostrando como o mercado está estruturado. Esta seção discorre também sobre as alterações normativas pelas quais a radiodifusão do país passou a partir da década de 2000 e posteriormente, aquelas trazidas pelos governos de Tabaré Vázquez (2005-2010) e de José Mujica (2010-2015). Por fim, são apresentados os resultados dessa análise comparativa da Lei 19.307, ainda a ser regulamentada pelo novo governo de Tabaré Vázquez - que retornou ao poder em 2015.

\section{O setor de radiodifusão no Uruguai}

Marcado historicamente por um forte caráter comercial, o setor uruguaio de radiodifusão é dominado por três grandes grupos de TV privada, que atuam nas modalidades rádio, TV aberta, por cabo e satélite: Romay-Salvo (canal 4), De Feo-Fontaina (Canal 10) e Cardoso-Scheck (Canal 12) (ARAÚJO, OLIVEIRA, 2013). Além de Montevidéu, os três grupos midiáticos são proprietários de estações e de redes de TV aberta e por assinatura nas cidades de Colonia, Meldonado e Rocha. O grupo Romay-Salvo é também titular do Canal 3 da cidade de Colonia e do Canal 8 de Rosário, que atualmente retransmitem seu Canal 4 de Montevidéu, além do canal por assinatura Del Faro TV (Colonia Telecable S.A.) (LANZA, BUQUET, 2011).

A Red Uruguaya de Televisión Sociedad Anónima (RUTSA ou Red) é uma empresa de propriedade acionária compartilhada por esses três conglomerados uruguaios para, basicamente, prover conteúdos aos permissionários de TV do interior do país. A Red conta com os canais que cada um dos grupos tem no interior e dois canais próprios do consórcio (Durazno e Paso de los Toros), planejando a programação e os espaços comerciais entre as mais de 20 emissoras de TV aberta no interior do país por meio de relações contratuais (LANZA, 2012).

Já a empresa Equital é a equivalente para a TV por assinatura. Desde sua criação, pelos mesmos três grupos, ela se constituiu num monopólio no mercado de TV paga que em seguida passou a concorrer com novos competidores: a Direct TV e o Grupo Clarín 
(argentino). Os canais associados são também proprietários do Multiseñal, um sistema de TVs por microondas sem fio que compete com o Grupo Clarín em Montevidéu (LANZA, 2012).

Quadro 1 - Propriedade e controle dos três principais grupos da televisão privada comercial do Uruguai

\begin{tabular}{l|l|l}
\hline Grupo & TV Aberta & TV por assinatura \\
\hline $\begin{array}{l}\text { Grupo Romay-Salvo } \\
\text { Romay-Eccher }\end{array}$ & $\begin{array}{l}\text { Canal 4 Dolores } \\
\text { Montecarlo TV S.A. (Canal } \\
\text { 4) } \\
\text { Canal 3 Colonia } \\
\text { Canal 8 Rosario } \\
\text { Canal 11 Punta del Este } \\
\text { Canal 12 Fray Bentos }\end{array}$ & $\begin{array}{l}\text { Monteclable (video S.A.) } \\
\text { Del Faro TV Cable (Colonia } \\
\text { Telecable S.A.) } \\
\text { Fray Bentos Video Cable }\end{array}$ \\
\hline Grupo Fontaina-De Feo & $\begin{array}{l}\text { Canal 7 Cerro Pan de } \\
\text { Azúcar 10 (Saeta) }\end{array}$ & $\begin{array}{l}\text { TCC (Tractoral S.A) } \\
\text { Rocha Cable Color } \\
\text { TDH Satelital }\end{array}$ \\
\hline $\begin{array}{l}\text { Canal 10 (Srupo Cardoso - Pombo } \\
\text { Canal 9 Rocha }\end{array}$ & $\begin{array}{l}\text { Canal 12 (Televisora } \\
\text { Larrañaga S.A.) }\end{array}$ & $\begin{array}{l}\text { Nuevo Siglo (Riselco S.A.) } \\
\text { Latinoamérica Televisión }\end{array}$ \\
\hline
\end{tabular}

Fonte: Elaboração própria com informações obtidas em Lanza e Buquet (2011).

No que se refere a faturamento, esses grupos controlam 95,5\% do mercado de TV aberta do país, $75 \%$ do negócio de TV paga em Montevidéu e 74\% dos assinantes em escala nacional (ARAÚJO, OLIVEIRA, 2013). Tal concentração é fruto de uma legislação permissiva que historicamente estruturou o setor de acordo com interesses arbitrários de empresários de comunicação, deixando também a comunicação pública marginalizada e um setor comunitário criminalizado. A radiodifusão comercial uruguaia esteve, até o fim de 2014, regida essencialmente pela Lei 14.670 e pelo Decreto 734/78 - ambos da fase ditatorial do país. 


\section{a) Panorama histórico das políticas de comunicação no Uruguai: principais discussões}

As primeiras normas regulatórias para o setor de radiodifusão surgem no Uruguai quando se aprova a Lei 8.557 em 19 de dezembro de 1920 e a Lei 8.390, em 13 de novembro de 1928. A primeira foi a lei responsável pela criação do Serviço Oficial de Difusão Radioelétrica (SODRE). Posteriormente, em 25 de julho de 1974, foi criada pelo Executivo a Administração Nacional de Telecomunicações (ANTEL), por meio do Decreto-Lei ${ }^{\circ} 14.235$, voltada para ser uma entidade estatal de prestação de serviços de telecomunicações nacional e internacional.

Em 23 de junho de 1977, foi aprovado o Decreto-Lei $n^{\circ} 14.670$ para substituir a Lei 8.390. Em 8 de novembro de 1984, o Decreto $n^{\circ} 15.671$ cria a Direção Nacional de Comunicações (DNC), vinculada ao Ministério da Defesa Nacional com as atribuições de administrar, defender e controlar o espectro nacional. Como em outros países da região, o arranjo regulatório uruguaio nasce planejado e centralizado pelo Estado, com este exercendo o monopólio da transmissão de dados através da ANTEL, apesar da presença forte da iniciativa privada na prestação de tais serviços.

Em agosto de 1990, foi editado o Decreto $\mathrm{n}^{\mathbf{0}} 349$, que passa a regulamentar o serviço de TV por assinatura. Sua operação deve ser também autorizada pelo Executivo, diante da assessoria do DNC, mas no caso de emissoras comunitárias, essa autorização dependia diretamente do DNC (RUBIO, 1994).

Já em 1991, uma série de alterações das competências do Executivo é trazida através da Lei 16.211, Lei de Empresas Públicas, que cria também a Comissão Nacional de Telecomunicações (CONTEL), uma agência reguladora dotada de autonomia técnica para controlar o setor (MENEZES, AGUM, 2013).

Até o ano 2000 não havia institucionalidade clara, salvo a Direção de Comunicação que se encontrava vinculada ao Ministério da Defesa e ligada a instrumentos antigos da ditadura militar. Era um pequeno escritório que fazia muito pouca coisa, com a TV, praticamente nada. Não se discutia nada. As três famílias já estavam consolidadas. Era apenas um controle mais técnico. Isso explica, por exemplo, porque os canais estavam organizados em números pares, para evitar interferências. Era o único controle. Nos anos 90, quando se 
abre o cabo, se criaram regras de jogo que impediram o surgimento de novos competidores, ficando mais centrado, mais uma vez nas três famílias. Era uma oportunidade de se abrir para novos atores, mas as outorgas eram feitas quase que somente com a regra de que tinha que ter experiência em TV. O negócio sempre ficou bem fechado, por isso estão tão preocupados com a digitalização (relato oral, KAPLÚN, 2013) ${ }^{3}$.

Somente em 2001 é criada a Unidade Reguladora de Serviços de Comunicações (URSEC), ao mesmo tempo em que se elimina a DCN e a CONTEL. A URSEC atua, a partir daí, como um órgão independente do Poder Executivo, mas sendo formada por uma comissão de três diretores indicados pelo Presidente da República (MENEZES, AGUM, 2013). Entre suas atribuições está a regulação de serviços de telecomunicaçõos, radiodifusão e postais, incluindo TV digital, TV a cabo, rádios comunitárias.

Em seguida o governo aprova o Decreto n 114 de 2003 (conhecido como Regulamento da Administração e Controle do Espectro Radioelétrico) e o Decreto n ${ }^{\circ} 115$ no mesmo ano, (o último intitulado Regulamento das Licenças de Telecomunicações). O primeiro regulamento coloca entre os objetivos da URSEC promover o uso do espectro radioelétrico como fator de desenvolvimento econômico e social e propiciar o acesso equitativo aos recursos radioelétricos, mediante procedimentos abertos, transparentes e não- discriminatórios. Já o segundo regulamento define novas regras de prestação de serviços de telecomunicações, com exceção dos de radiodifusão por já possuírem regulamento próprio.

A partir de 2005, o país passa a viver a intensificação dos debates sobre a regulação do setor de comunicações. Isso ocorre, especialmente, com a eleição de Tabaré Vásquez para a presidência, quando o país inicia um amplo processo de reformas que se expandem pelo governo do presidente José Alberto Mujica.

\section{b) Reformas regulatórias recentes e o caminho para a nova lei}

Tabaré Vázquez (2005-2010 - Frente Amplio) foi o primeiro governo de esquerda a ascender à presidência depois de 175 anos de governos conservadores. Segundo Lanza (2012) é também o primeiro a adotar uma agenda mais progressista para a área de 
comunicação, tentando tornar exercício da liberdade de expressão e do direito à informação mais ampliado aos cidadãos.

Por tal razão, houve um aumento de expectativa para que um processo de reforma mais ampla se desse no setor, incluindo um diálogo com a sociedade civil. Entre as primeiras alterações que ocorreram estão a transferência dos temas da comunicação do Ministério da Defesa para o Ministério de Indústria, Energia e Minérios (pelo Decreto no 515/05) e a concessão de frequências para veículos de alcance local, mas o maior destaque naquele momento, sem dúvida, foi a aprovação da lei de radiodifusão comunitária.

Lanza e Goldaracena (2009) percebem a Lei n 18.232 de 2006 como um divisor de águas na ultrapassada legislação de comunicação do país. Pela primeira vez se instala um processo de concessão e renovação de permissões com princípios de transparência, participação e competição equilibrada, através de editais e audiências públicas. Algo distante, afirma Kaplún (2013), do tradicional esquema uruguaio, a partir do qual o governo arbitrariamente realizava concessões precárias e sem prazo. Com a lei nova, emissoras comunitárias têm estabelecido um prazo de 10 anos e sua renovação é condicionada ao cumprimento de compromissos de contrato, bem como a realização de uma audiência pública (URUGUAY, 2007). Um conselho assessor começa a fiscalizar a lisura nas concessões e renovações das licenças.

A lei de radiodifusão comunitária traz também uma compreensão mais ampliada sobre o interesse público do setor: "O espectro radioelétrico é um patrimônio comum da humanidade, sujeito a administração dos Estados e, portanto, o acesso equitativo as frequências por toda a sociedade uruguaia constitui um princípio geral de sua administração" (URUGUAY, 2007, tradução nossa). ${ }^{4} \mathrm{O}$ texto também determina a reserva de um terço das frequências disponíveis em AM e FM, enquadrando as emissoras comunitárias como terceiro setor complementar às rádios comerciais e estatais, além de poderem ter ainda canais de televisão.

Mais recentemente, a Lei $\mathrm{n}^{\circ} 17.930$ cria a Direção Nacional de Telecomunicações (DINATEL) para ser um órgão competente para formular, implementar, articular, coordenar e supervisionar as políticas nacionais do setor de telecomunicações como um 
todo, retirando essa atribuição da URSEC e deixando-a responsável somente pela regulação e fiscalização dos agentes de mercado.

O segmento de TV por assinatura também sofre reformulação com o Decreto 775, de 31 de dezembro de 2012. Ele procura criar barreiras para a formação de oligopólios no segmento ao determinar que o total de assinantes de cada empresa de TV paga não poderá ultrapassar $25 \%$ do total de residências uruguaias e que o total de assinantes das referidas empresas não poderá superar $35 \%$ do total de residências de cada território.

Num balanço sobre as políticas de comunicação do governo de Vázquez, Kaplún (2013) analisa que as mudanças foram poucas e que, em sua maioria, não eram iniciativas do governo e sim, nasciam das bases, isto é, com proposições feitas pela sociedade civil nãoempresarial. Ele destaca, além da aprovação da lei de radiodifusão comunitária, a aprovação de lei de acesso à informação pública (que determina que toda informação de Estado deve se tornar pública, a não ser em situações específicas de necessidade de sigilo).

As expectativas sobre o aprofundamento das reformas para o setor das comunicações se mantiveram em 2010 quando José Mujica, ex-integrante do Movimiento de Liberación Nacional-Tupamaros, e também membro do Frente Amplio, é eleito presidente. Foi iniciado no Uruguai, a partir daí, um processo de discussão para uma nova lei de serviços de comunicação audiovisual. É convocado, então, o Comitê Técnico Consultivo (CTC) para a nova Lei de Serviços de Comunicação Audiovisual (LSCA) pela DINATEL em julho de 2010, com o objetivo de estabelecer um espaço institucionalizado de diálogos entre os diferentes atores em torno da temática. De acordo com Kaplún (2013), o CTC foi produtivo e tornou-se um ambiente no qual atores estatais, empresariais, sociais e acadêmicos puderam intercambiar informações e opiniões para se pensar em uma lei geral para o setor.

Diversos consensos foram alcançados em reuniões semanais ocorridas entre 6 de agosto e 19 de novembro de 2010, e relatados no Informe-Síntese final. Dentre diversas outras coisas, o relatório recomendava que uma nova lei deveria assimilar a convergência 
tecnológica, utilizando o conceito de Serviços de Comunicação Audiovisual (SCA), de modo a abarcar serviços diversos independente da tecnologia de suporte utilizada.

Entende-se por SCA um serviço cuja principal finalidade é proporcionar programas com o objetivo de informar, entreter ou educar, através de redes de comunicações eletrônicas, de televisão ou radiodifusão sonora por meio de uma oferta estável e permanente de conteúdos, sobre a base de um horário de programação (INFORME-SÍNTESIS, 2010, p. 03,) ${ }^{5}$.

A iniciativa inédita para o setor de comunicações uruguaio - embora tenha sido reconhecida como um debate de alto nível, além de transparente, participativo e aberto teve seu resultado rechaçado pelo chefe do Executivo em 2010. Após quatro meses de encontros e trabalho, na divulgação de seu relatório final, os representantes do CTC foram surpreendidos com declarações de Mujica de que

(...) a melhor lei é a que não existe (...). Estão me cansando com essa pergunta [referindo-se à futura Lei de Serviços de Comunicação Audiovisual]. Cansando! Ao governo não trouxeram nada, mas quando o fizerem, eu vou jogar no lixo" (SI ME TRAEN..., 2010, s/p, $)^{6}$.

Contudo, segundo Lanza (2012), a iniciativa serviu para fortalecer a organização da sociedade civil, que apresentou propostas e fundamentou suas pautas. Em dezembro de 2010, a Coalizão da Sociedade Civil por uma Política Democrática de Comunicação (CSCPDC) - coletivo de organizações da sociedade civil - apresentou 16 pontos que deveriam ser contemplados, como: concentração de propriedades no setor, outorgas de concessões, diversidade e direitos das audiências. Os documentos foram entregues ao Ministério da Indústria, Energia e Minérios para que uma proposta de Lei de Serviços de Comunicação Audiovisual fosse elaborada (AMARC, 2010).

Um projeto é, então, redigido em conformidade com instrumentos internacionais assinados pelo país, como a Convenção sobre a Proteção e Promoção da Diversidade de Expressões Culturais da UNESCO, planejando uma abordagem integral do setor no sentido de cobrir vazios legais existentes. 


\section{Análise empírica do cenário uruguaio}

Durante o ano de 2014, os debates sobre a nova lei se intensificaram no Uruguai de modo que, em 22 de dezembro de 2014, ela foi aprovada com 50 votos favoráveis e 25 contrários na Câmara dos Representantes do país. A Lei no 19.307, promulgada em 29 de dezembro de 2014 ainda por José Mujica e publicada em 14 de janeiro de 2015, possui 202 artigos e estava prevista para ser regulamentada até maio de 2015, já pelo novo governo de Tabaré Vazquéz.

A presente seção dedica-se a discutir os resultados obtidos em uma aproximação analítica realizada a partir da aplicação das categorias de indicadores abaixo discriminadas. Esses indicadores já haviam sido aplicados à legislação do país em pesquisa anterior ${ }^{7}$ e agora servem de parâmetro para uma primeira discussão comparativa dessa nova lei.

Quadro 2 - Categorias de indicadores aplicados

\begin{tabular}{|c|c|c|}
\hline Categoria & Indicadores & Questões \\
\hline $\begin{array}{l}\text { Valores } \\
\text { democráticos }\end{array}$ & $\begin{array}{l}\text { - Funções e objetivos do serviço } \\
\text { de TV } \\
\text { - Reconhecimento expresso de } \\
\text { valores como direito à } \\
\text { comunicação, liberdade de } \\
\text { expressão, interesse público, } \\
\text { diversidade etc. }\end{array}$ & $\begin{array}{l}\text { - Quais as funções e objetivos do } \\
\text { serviço de TV? } \\
\text { - Como se dá o reconhecimento } \\
\text { expresso de valores como direito à } \\
\text { comunicação, liberdade de expressão, } \\
\text { interesse público, diversidade etc.? }\end{array}$ \\
\hline $\begin{array}{l}\text { Autoridades } \\
\text { reguladoras }\end{array}$ & $\begin{array}{l}\text { - Distribuição de poderes } \\
\text { - Financiamento } \\
\text { - Constituição do corpo diretivo } \\
\text { - Accountability } \\
\text { - Liberdade para autorregulação }\end{array}$ & $\begin{array}{l}\text {-Como se dá a distribuição de poderes } \\
\text { entre entidades reguladoras do setor? } \\
\text { - Quais são as regras de financiamento } \\
\text { dessas entidades? } \\
\text { - Como é prevista a constituição do } \\
\text { corpo diretivo? } \\
\text { - Quais as regras para accountability } \\
\text { - Como está prevista a liberdade para } \\
\text { autorregulação? }\end{array}$ \\
\hline $\begin{array}{l}\text { Licenciamento } \\
\text { (outorgas de } \\
\text { concessões) }\end{array}$ & $\begin{array}{l}\text { - Divulgação da disponibilidade } \\
\text { de licenças } \\
\text { - Processo de licenciamento e } \\
\text { renovação } \\
\text { - Condições estabelecidas na } \\
\text { licença } \\
\text { - Sanções }\end{array}$ & $\begin{array}{l}\text { - Como se dá a divulgação de } \\
\text { disponibilidade de licenças? } \\
\text { - Como é o processo de licenciamento } \\
\text { e renovação? } \\
\text { - Quais as condições estabelecidas aos } \\
\text { prestadores de serviço na licença? } \\
\text { - Quais as sanções previstas? }\end{array}$ \\
\hline
\end{tabular}




\begin{tabular}{|c|c|c|}
\hline $\begin{array}{l}\text { Regras de } \\
\text { propriedade }\end{array}$ & $\begin{array}{l}\text { - Concentração de propriedade } \\
\text { - Capital estrangeiro } \\
\text { - Propriedade por detentores de } \\
\text { cargos públicos }\end{array}$ & $\begin{array}{l}\text { - Como funcionam os instrumentos } \\
\text { voltados para evitar concentração de } \\
\text { propriedade? } \\
\text { - Como são as regras relativas a } \\
\text { entrada de capital estrangeiro? } \\
\text { - Como funcionam as regras relativas à } \\
\text { propriedade de emissoras por parte de } \\
\text { detentores de cargos públicos? }\end{array}$ \\
\hline $\begin{array}{l}\text { Regulação de } \\
\text { conteúdo }\end{array}$ & $\begin{array}{l}\text { - Diversidade } \\
\text { - Proteção de crianças e } \\
\text { adolescentes } \\
\text { - Proteção contra incitação a } \\
\text { crime e discursos de ódio } \\
\text { - Direito de resposta } \\
\text { - Publicidade } \\
\text { - Regras e instrumentos para } \\
\text { queixas } \\
\text { - Sanções } \\
\text { - Previsão de controle prévio de } \\
\text { conteúdo (censura) } \\
\text { - Obrigações positivas de } \\
\text { conteúdo: cotas de produção } \\
\text { nacional, estímulo a produção } \\
\text { independente e ao conteúdo } \\
\text { regional. }\end{array}$ & $\begin{array}{l}\text { - Como é feita referência a noção de } \\
\text { diversidade de conteúdo? } \\
\text { - Como está prevista a proteção de } \\
\text { crianças e adolescentes nas regras do } \\
\text { setor? } \\
\text { - Como se dá a proteção contra } \\
\text { incitação a crime e discursos de ódio? } \\
\text { - Como está previsto o direito de } \\
\text { resposta? } \\
\text { - Quais são as regras para a } \\
\text { publicidade na TV? } \\
\text { - Como funcionam as regras e } \\
\text { instrumentos para queixas? } \\
\text { - Como funcionam as sanções em caso } \\
\text { de violação de conteúdo? } \\
\text { - Existe alguma previsão de controle } \\
\text { prévio de conteúdo? } \\
\text { - Como se estabelecem as cotas e } \\
\text { estímulos para produção nacional, } \\
\text { independente e regional? }\end{array}$ \\
\hline $\begin{array}{l}\text { Emissoras } \\
\text { públicas }\end{array}$ & $\begin{array}{l}\text { - Transparência e accountabillity } \\
\text { - Independência } \\
\text { - Financiamento e gestão }\end{array}$ & $\begin{array}{l}\text { - Quais as regras de transparência e } \\
\text { accountability para emissoras públicas? } \\
\text { - Existem instrumentos para assegurar } \\
\text { sua independência? } \\
\text { - Como estão previstos seu } \\
\text { financiamento e gestão? }\end{array}$ \\
\hline $\begin{array}{l}\text { Emissoras } \\
\text { comunitárias }\end{array}$ & $\begin{array}{l}\text { - Reconhecimento e } \\
\text { enquadramento legal } \\
\text { - Financiamento e gestão } \\
\text { - Licenciamento }\end{array}$ & $\begin{array}{l}\text { - Existem instrumentos para } \\
\text { reconhecimento e enquadramento legal } \\
\text { das emissoras comunitárias? } \\
\text { - Como estão previstos seu } \\
\text { financiamento e gestão? } \\
\text { - Como se dá seu licenciamento? }\end{array}$ \\
\hline Inovação & $\begin{array}{l}\text { - Transição para a tecnologia } \\
\text { digital }\end{array}$ & $\begin{array}{l}\text { - Como está prevista a transição para a } \\
\text { tecnologia digital nos instrumentos } \\
\text { normativos do setor? }\end{array}$ \\
\hline Controle público & $\begin{array}{l}\text { - Participação e controle social } \\
\text { em mecanismos de } \\
\text { monitoramento }\end{array}$ & $\begin{array}{l}\text { - Existem instrumentos de participação } \\
\text { e controle por parte da sociedade civil? }\end{array}$ \\
\hline
\end{tabular}

Fonte: TORQUATO, 2014.

\section{a) Análise comparativa de resultados}


A nova lei traz maior reflexão acerca da influência desse setor na sociedade, trazendo o termo Serviços de Comunicação Audiovisual (SCA) para referir-se a indústrias culturais, portadoras de informações, opiniões, ideias, identidades, valores, significados e que, por conseguinte, não devem ser considerados unicamente pelo seu valor comercial. Os SCA são vistos como suportes técnicos para o exercício do direito humano à liberdade de expressão e de informação que, por sua vez, são preexistentes à qualquer intervenção estatal. Assim, no que se refere à categoria valores democráticos, é possível observar a superação de definições antes essencialmente técnicas, como aquelas trazidas pelo Decreto-Lei 14.670/77 - em que a radiodifusão é colocada meramente como emissões sonoras, televisivas ou similares destinadas à recepção direta pelo público.

O novo texto coloca entre as finalidades para os SCA: o exercício do direito à livre expressão de informações e opiniões; a garantia do direito das pessoas de acessar a uma pluralidade de informações e opiniões; a facilitação do debate democrático e promoção da participação democrática nos assuntos públicos; a elaboração e fomento da produção de conteúdos nacionais; o emprego de mão-de-obra artística, técnica e cultural nacionais; a difusão e promoção da identidade nacional, do pluralismo e diversidade cultural do país; a não discriminação e o apoio à integração social de grupos sociais vulneráveis (URUGUAY, 2015).

A noção de interesse público que havia na legislação anterior, o Decreto-Lei 14.670/77, é mantida. O artigo 6 da nova lei declara que os SCA são de interesse público; por constituírem um dos principais meios de informação social, permitem o exercício do direito de comunicar e receber informações para o exercício pleno da liberdade de expressão e da cidadania, difusão de valores como a identidade e a diversidade cultural, e apoio à educação - compondo um sistema essencial para a promoção da convivência, integração social, igualdade, pluralismo e valores democráticos. Eles permanecem podendo ser prestados por pessoas físicas ou jurídicas, privadas ou públicas, estatais ou não estatais, em regime de autorização ou licença. Além disso, o acesso universal aos SCA é obrigação do Estado e deve assegurar a inclusão social de toda a população.

Promoção do pluralismo, da diversidade, da não-discriminação, da transparência dos processos de outorga, garantia à liberdade editorial, o incentivo à produção nacional e 
independente são valores reiteradamente mencionados em diversos artigos da nova lei. Existem capítulos específicos para direitos das pessoas, direitos de crianças e adolescentes, das pessoas com deficiência, direito ao acesso a eventos de interesse geral, direitos dos jornalistas, direitos dos prestadores de SCA, um capítulo específico para tratar de diversidade e pluralismo e outro para promoção da produção audiovisual nacional.

Relativos à categoria entidades reguladoras, continuam a Direção Nacional de Telecomunicações e Serviços de Comunicação Audiovisual (DINATEL) - responsável pelo setor dentro do Ministério da Indústria, Energia e Minérios - e a Unidade Reguladora de Serviços de Comunicações (URSEC), que deve controlar a qualidade e a regularidade na prestação do serviço pelos operadores, realizar a supervisão técnica e aplicar sanções, quando necessário. As novidades são, portanto, o Conselho de Comunicação Audiovisual, a Comissão Honorária Assessora dos Serviços de Comunicação Audiovisual e a Defensoria do Público.

Criado como órgão independente do Executivo para fiscalizar a aplicação da lei, o Conselho de Comunicação Audiovisual (CCA) deve, de acordo com o artigo 67, atuar em função do interesse geral, protegendo e promovendo o exercício da liberdade de expressão, direito à informação e os direitos culturais de todas as pessoas. O órgão deve elaborar seu próprio regimento interno, monitorar as políticas do setor e a gestão do Sistema Público de Rádio e Televisão Nacional (SPRTN) e também promover educação para a mídia, desenvolver um observatório de audiovisual para sistematizar dados estatísticos sobre o setor, fiscalizar os direitos de usuários, das crianças e adolescentes, realizar consultas à audiência, prevenir práticas concorrenciais desleais ou formação de oligopólios, entre outras ações. O artigo 69 reitera que, embora vinculado administrativamente ao ministério do setor, esse órgão possui autonomia técnica (URUGUAY, 2015).

O Conselho conta recursos advindos de taxas recebidas dos operadores do setor (entes públicos ou privados), multas, além de doações e outros valores que sejam resultados de sua gestão. Deve ser composto por cinco membros com regime de dedicação total, incluindo um presidente. $\mathrm{O}$ mandato é de três anos, podendo ser prorrogado uma vez. $\mathrm{O}$ 
presidente do conselho é designado pelo Presidente da República em acordo com o Conselho de Ministros, e tem seu mandato a ele vinculado. Os outros quatro membros devem ser eleitos pela Assembleia $\mathrm{Geral}^{8}$.

A Comissão Honorária Assessora de Serviços de Comunicação Audiovisual (CHASCA), por sua vez, substitui a Comissão Honorária Assessora de Serviços de Radiodifusão Comunitária e a Comissão Honorária Assessora Independente, e deve atuar também de modo autônomo na órbita administrativa do Conselho de Comunicação Audiovisual. Ela deverá ser consultada obrigatoriamente para a elaboração do regulamento da nova lei, para os procedimentos de outorgas e sempre que o Executivo ou o Conselho julgarem necessário. Deve ser integrada por representantes: do Ministério da Indústria, Energia e Minérios (que o presidirá), do Ministério da Educação e Cultura, da Universidade da República, das universidades privadas, dos operadores do setor comercial, do setor comunitário, dos trabalhadores do setor, da indústria audiovisual, do Instituto da Criança e do Adolescente do Uruguai, três representantes de ONGs, e um membro do Legislativo (URUGUAY, 2015).

Além disso, a Instituição Nacional de Direitos Humanos e Defensoria do Povo - criada pela lei 18.446 de 2008 - passa defender e promover os direitos humanos junto aos SCA, velando pela qualidade e regularidade desses serviços, recebendo e encaminhando denúncias, designando um Relator Especial para os SCA, elaborando um registro de denúncias recebidas, informes periódicos e coordenando um Plano Nacional de Educação para a Comunicação.

Para o setor de SCA público surge a Comissão Honorária Assessora do Sistema Público de Rádio e Televisão Nacional, com compromissos de assessorar o diretório do Sistema Público de Rádio e Televisão Nacional (SPRTN), receber e gerir queixas relativas à sua programação e propor modificações, inclusive normativas. ${ }^{9}$ A Comissão Honorária Assessora do Sistema Público de Rádio e Televisão Nacional é integrada por representantes dos trabalhadores do Sistema Público de Rádio e Televisão Nacional (SPRTN), do sindicato nacional de trabalhadores, da Associação de Imprensa, da Universidade da República, de associações civis que trabalhem com a temática de comunicação pública, da Assembleia Geral, do Instituto da Criança e do Adolescente, da 
Administração Nacional de Educação Pública, dos cidadãos usuários e dos prefeitos (URUGUAY, 2015).

Outra novidade é que o texto da lei 19.307/15 prevê expressamente, em seus artigos 146 e 147, a autorregulação ética ou de conduta profissional dos titulares de SCA, que devem exercer suas atividades conforme códigos, de caráter individual ou coletivo, tornados públicos, devendo ser determinados livremente por cada prestador. Além disso, o artigo 148 define que o Estado solicitará aos titulares de SCA que designem, também de modo individual ou coletivo, um defensor da audiência com a responsabilidade de receber e responder às demandas e reclamações do público.

No que diz respeito à categoria licenciamento, algumas mudanças foram realizadas de modo a inserir maior controle do CCA e da CHASCA nesse processo. O Poder Executivo outorgará os sinais mediante chamada pública, estudo técnico prévio da URSEC e com a realização de consulta pública e avaliação da CHASCA sempre que a administração julgar necessário ou a cada cinco anos.

Em caso de mais interessados do que frequências, deverá ser aberto um concurso público, e no caso de um único interessado a proposta deverá ser avaliada pelo CCA - que a levará para o Executivo autorizá-la ou não. Orientando-se pelos princípios de transparência e publicidade, o Conselho deverá publicar informações sobre os candidatos e poderá, quando julgar necessário, realizar consultas ou audiências públicas na localidade onde o serviço pretende ser prestado. Esses procedimentos também podem ser utilizados nos casos de renovação ou transferência de titularidade.

Estabelece-se também os prazos de duração das autorizações em dez anos para rádio e 15 para TV. A solicitação de renovação deve ser realizada pelo menos 12 meses antes do fim do prazo desde que o titular mantenha os requisitos exigidos por lei, que cumpram as obrigações assumidas (como o projeto comunicacional proposto no ato do concurso), que tenham um relatório técnico favorável da URSEC, não possuam dívidas com a Administração e não tenham recebido três ou mais sanções graves pelo descumprimento de regras. O Executivo não poderá realizar novas concessões de outorgas num período de 12 meses anteriores e 6 meses posteriores a pleitos eleitorais (URUGUAY, 2015). 
Sobre as autorizações vigentes, que haviam sido outorgadas em caráter precário e que são revogáveis, o artigo 194 institui que elas expiraram no momento da promulgação na nova lei. Por esta razão, o Executivo deverá iniciar novo processo de concessão aos atuais titulares, agora correndo os novos prazos e regras estabelecidas.

Permanecem as regras de que os candidatos devem ser uruguaios ou naturalizados, domiciliados no país (devendo as ausências prolongadas serem justificadas), ter idoneidade, capacidade econômica (depositando garantia) e declarar se possuem participação em algum outro serviço de comunicação. A transferência de titularidade deve ocorrer apenas mediante autorização prévia do Executivo e do CCA. O arrendamento é expressamente proibido pelo artigo 112.

Para operadores de SCA por assinatura, entre as condições de licenciamento está a reserva para os sinais das TVs abertas, comerciais púbicas ou comunitárias em seu pacote básico, além do must carry de três sinais nacionais de televisão sem vínculo com outros serviços de TV aberta ${ }^{10}$.

A categoria regras de propriedade também apresenta alterações significativas com a nova lei uruguaia. $\mathrm{O}$ art. 51 estabelece que monopólios e oligopólios na titularidade ou controle dos SCA conspiram contra a democracia ao restringir o pluralismo e a diversidade fundamental do pleno exercício do direito à informação das pessoas, sendo dever do Estado coibi-los. Cria-se, portanto, o Registro de Serviços de Comunicação Audiovisual com o propósito de promover a transparência na titularidade dos SCA. Para a TV aberta, as limitações são: uma pessoa física ou jurídica privada não pode ter a titularidade, total ou parcial, de mais de três autorizações para SCA aberta de rádio ou TV, nem mais de duas para a prestação de radiodifusão aberta na mesma banda de frequências - AM, FM e TV - em todo território nacional.

Já no caso de TV por assinatura: uma pessoa física ou jurídica privada não pode ser beneficiada com a titularidade de mais de seis autorizações ou licenças em território nacional, nem mais de uma autorização ou licença para um mesmo âmbito de cobertura local. O número de seis se reduzirá para três no caso de uma dessas autorizações se localizar em Montevidéu (URUGUAY, 2015). Existe ainda limitação para a quantidade 
de assinantes no caso de TV paga. Agora o número total por empresa não pode ultrapassar $25 \%$ do total de casas com TV por assinatura no país. Além disso, aqueles que já prestem serviços de SCA não poderão prestar serviços de telefonia ou de transmissão de dados. No que se refere à retransmissão, os serviços de radiodifusão privados não poderão exceder $70 \%$ de seu tempo com emissão diária de retransmissão de outro sinal, salvo exceções autorizadas pelo Executivo e pelo CCA.

Numa prevenção a uma prática comum em mercados de TV latino-americanos, a nova lei uruguaia previne o uso de nome de parentes para a manutenção de licenças, como define o item "F" do art. 105 (URUGUAY, 2015). Em nenhum caso poderá ser titular de autorização ou licença cônjuge, companheiro, parente por afinidade ou biológico, em linha reta, lateral, até segundo grau, de titulares de SCA, sempre que esses sujeitos infrinjam os limites de titularidade previstos nos artigos 53 e 54 da Lei 19.307/15. Para adequação a essas normas de anti-concentração, o artigo 189 da nova lei estabelece o prazo de quatro anos para a transferência da titularidade das autorizações ou licenças excedentes.

Em relação à entrada de capital estrangeiro no setor, a autorização que havia pela lei 14.179/74 é derrubada. A nova lei uruguaia define no artigo 106 que, para SCA aberta, pessoas jurídicas aspirantes a titular não podem ter vinculação jurídica societária, nem sujeição direta ou indireta com SCA estrangeiras, ser filiais ou subsidiárias de sociedades estrangeiras, ou realizar contratos societários que permitam uma posição dominante do capital estrangeiro na condução da pessoa jurídica societária. Já para SCA por assinatura, no caso de titularidade por uma sociedade será admitido que os requisitos acima sejam cumpridos por no mínimo $51 \%$ do capital acionário, devendo essa percentagem ter direito a voto (URUGUAY, 2015).

Não foram encontradas especificações relativas à propriedade de emissoras de SCA por detentores de cargos públicos no marco legal uruguaio. Permanece apenas a proibição da transmissão de conteúdo que configure proselitismo político-partidário pela lei de radiodifusão comunitária. 
Importantes alterações podem ser observadas também ao se analisar a categoria regulação de conteúdo. A nova lei passa a complementar o já existente Código da Infância e da Adolescência (Lei $\mathrm{n}^{\circ}$ 17.823). De acordo com a lei de 2015, é dever do Estado através do CCA e da DINATEL velar pelo público de crianças e adolescentes em relação aos conteúdos de SCA. O texto informa que esses órgãos devem incentivar conteúdos que promovam seu bem-estar social, sua saúde física e mental, desenvolver formas de educação, de pesquisa sobre a área de mídia e infância e de estimular boas práticas de responsabilidade social empresarial com autorregulação.

Crianças e adolescentes também mantêm o direito de ter sua identidade preservada em informações divulgadas que possam lhes prejudicar. O horário de proteção estabelecido para esse público é entre $6 \mathrm{~h}$ e $22 \mathrm{~h}$, período em que a programação poderá oferecer recomendações para orientar o público sobre o conteúdo adequado para cada faixa etária. Nesse horário, a programação deve evitar conteúdos que exibam ou façam apologia à violência excessiva, comportamentos criminosos, discriminatórios ou conteúdo pornográfico.

As mensagens publicitárias também não podem dirigir-se diretamente às crianças e adolescentes ou aproveitar-se de sua lealdade a pais e professores, devendo seguir recomendações internacionais relativas a alimentos com alto teor de gordura, sal ou açúcar. Além disso, crianças e adolescentes não podem atuar em qualquer comercial de produtos que prejudiquem sua saúde ou integridade física, psicológica ou social. Ainda sobre conteúdo publicitário, o art. 139 o restringe, a 15 minutos por hora de programação em rádio e TVs tanto na TV aberta como por assinatura. A nova lei especifica também que o volume de áudio deve ser igual ao do resto da programação, e que durante a exibição de filmes e documentários o bloco ente comerciais deverá ter no mínimo 30 minutos. Ficam proibidos canais de TV aberta com conteúdo exclusivamente publicitário e também o uso de publicidade oculta ou subliminar (URUGUAY, 2015).

Ainda sobre regulação de conteúdo, o art. 28, no âmbito dos direitos das pessoas, define que não poderão ser difundidos pelos SCA conteúdos que incitem ou façam apologia à discriminação e ao ódio nacional, racial ou religioso, que constituam incitações à violência ou qualquer outra ação ilegal similar contra qualquer pessoa ou grupo de 
pessoas, motivada por raça, etnia, sexo, gênero, orientação sexual, identidade de gênero, idade, deficiência, identidade cultural, lugar de nascimento, credo ou condição socioeconômica. $\mathrm{O}$ artigo 43 garante que qualquer pessoa, física ou jurídica, possa entrar com uma ação judicial para denunciar e solicitar a aplicação de sanções em casos de violação.

Em vários momentos, o texto da lei reitera a proibição à censura. $\mathrm{O}$ artigo 8 estabelece que a regulação do Estado deve acontecer sempre posteriormente, de modo a prevalecer a sua obrigação de garantir, proteger e promover o direito à liberdade de expressão e de informação de toda a sociedade. Fica estabelecido também que o exercício das funções do Estado deve tornar possível o mais amplo, livre e independente exercício da liberdade de expressão, e que nunca poderá ser utilizado como uma forma de censura indireta. ${ }^{11}$

No que diz respeito a cotas de conteúdo, de acordo com o art. 60, os SCA abertos e por assinatura, comerciais ou públicos devem passar a incluir em sua programação ao menos $60 \%$ de produção ou co-produção nacional, sendo uma porcentagem a ser determinada por regulamentação específica para produção de fora de Montevidéu. Além disso, ao menos $30 \%$ dessa programação deve ser de produtores independentes, não podendo um mesmo produtor independente ocupar mais de $40 \%$ de um mesmo serviço de radiodifusão. Um mínimo de duas horas por semana de programação emitida deverá conter lançamentos nacionais de ficção televisiva ou de filmes e, desses, pelo menos $50 \%$ deverão ser de produção independente. Ao menos dois filmes nacionais devem ser transmitidos no horário entre as $19 \mathrm{~h}$ e $23 \mathrm{~h}$ por ano., A programação deve promover também a indústria criativa (teatro, dança, artes visuais, museus, música, livros, cinema, videogames, desenhos, etc.), sendo pelo menos $50 \%$ dedicada à produção nacional, em um mínimo de duas horas por semana. O prazo de adequação nesse quesito é de no máximo dois anos.

As infrações a quaisquer dessas normas são passíveis de sanções. Os tipos de infrações podem ser, de acordo com o art. 177, leves, graves e muito graves, e devem ser aplicadas segundo sua gravidade ou reincidência. Conforme artigo 181, elas podem ser: observação, intimação, apreensão de equipamentos ou elementos utilizados para cometer a infração; multa, suspensão de até 90 dias da prestação da atividade e, em casos de 
infrações muito graves, revogação da concessão, autorização, licença ou registro (URUGUAY, 2015).

Também há mudanças na categoria emissoras públicas. Para substituir a antiga SODRE, a nova lei cria o Sistema Público de Rádio e Televisão Nacional (SPRTN) com o objetivo de desenvolver um serviço considerado fundamental para a comunidade uruguaia, contendo informação, cultura, educação e entretenimento, e buscando consolidar a cidadania. Deve promover valores de paz, democracia, integração, justiça social, nãodiscriminação, proteção ao meio ambiente, inclusão social de grupos vulneráveis, liberdade de expressão, igualdade dos cidadãos, pluralismo e participação, informação com independência editorial e de programação, além de auxiliar no desenvolvimento cultural, educativo e artístico de localidades mais afastadas da capital. Deve ainda satisfazer as necessidades de informação, cultura, educação e entretenimento do público, garantir o acesso de distintos grupos sociais e políticos, promover a produção nacional e independente e fomentar a colaboração com a produção latino-americana.

A diretoria do SPRTN é definida diretamente pelo Executivo. As diretorias da rádio e da TV são por ela designadas e devem aprovar junto à mesma os planos anuais, além de oferecer informes periódicos, justificando medidas adotadas (URUGUAY, 2015). Os membros de quaisquer diretórios não podem ter vínculos diretos ou indiretos com emissoras ou empreendimentos comerciais ligados a rádio, TV, publicidade, comunicação ou similar durante o período de sua gestão. O artigo 169 define que as disposições relativas ao procedimento administrativo geral devem orientar-se pelos princípios da imparcialidade, legalidade objetiva, verdade material, eficácia, entre outros. O seu patrimônio físico - assim como suas dívidas, fundos e obrigações - são herdados da antiga SODRE.

No que se refere à categoria Emissoras comunitárias, permanece a já mencionada Lei $\mathrm{n}^{\circ}$ 18.232, apenas com a alteração que institui a CHASCA.

Relativo à categoria Inovação, é notável que, embora use a expressão "serviço de comunicação audiovisual" (seguindo tendência de regulação convergente) e se volte para 
unificar leis antes dispersas, a nova lei exclui internet. Existem também poucas referências a serviços de rede ou de interatividade no texto da lei.

A categoria Controle público, como foi visto, encontrou-se contemplada na nova legislação com a criação de instrumentos como Comissão Honorária Assessora de Serviços de Comunicação Audiovisual (CHASCA), a Comissão Honorária Assessora do Sistema Público de Rádio e Televisão Nacional e a figura da defensoria do público, já descritos acima. Além disso, o artigo 27 estabelece, ainda, que o Poder Executivo deve oferecer mecanismos de participação cidadã no processo de elaboração e fiscalização de políticas públicas para o setor de SCA.

\section{Considerações finais}

A legislação anterior uruguaia não assegurava pluralidade e diversidade, nem mesmo a consignação de frequências de modo transparente; além disso, favorecia a manutenção de oligopólios e da grande concentração no setor privado. Tratava-se de uma legislação dispersa e ineficiente, dissolvida em decretos para tratar de diferentes aspectos da comunicação social (RUBIO, 1994). O marco legal anterior era herança de um período ditatorial e conferia grande arbitrariedade ao poder político para administrar o espectro radioelétrico. Foi um modelo capaz de permitir a concessão de licenças aos três grandes grupos dominantes do setor de forma precária e irrevogável desde 1950 e, embora houvesse algumas poucas normas específicas - tais como o limite a publicidade e a impossibilidade de transferência da concessão - elas sempre foram fortemente descumpridas, pois não havia um sistema claro de fiscalização e punição. ${ }^{12}$

A aprovação da nova lei, portanto, oferece o primeiro passo para a superação desses desafios. O texto supera determinações meramente tecnológicas, incorporando reflexões políticas e sociais acerca de valores democráticos diversos, como pluralidade, diversidade, liberdade de expressão, direito à informação, direito à comunicação, transparência e participação. Seus princípios orientam-se por disposições consagradas na Declaração Universal dos Direitos Humanos, na Convenção Americana sobre direitos 
Humanos e o Pacto Internacional de Direitos Civis e Políticos. Ele institucionaliza formas de participação social, renova o setor público, cria normas de conteúdo e procura avançar, com regras mais claras, na desconcentração do setor, protegendo a identidade e cultura nacional.

Além disso, oferece referência legal para evitar excessos do Estado, assim como referência específica para defesa do público em geral, da diversidade de etnias, orientações, gênero, crenças e posturas políticas, direitos de crianças e adolescentes, pessoas com deficiência, jornalistas, radiodifusores. O novo texto institucionaliza um novo marco que mantém e aprimora as conquistas alcançadas recentemente, como as do decreto de digitalização da TV (com novas regras de licenciamento e anti-concentração) e a normativa da comunicação comunitária.

Por outro lado, a nova legislação ainda vincula ao Executivo os cargos diretivos das principais autoridades reguladoras do setor, assim como centraliza no mesmo a concessão de outorgas - o que, em última instância, pode comprometer a independência do sistema. Além disso, a nova legislação não esclarece restrições à propriedade de SCA por detentores de cargos públicos e desconsidera integrações tecnológicas dos SCA com a internet, sob o argumento que regulações específicas ainda devem ser desenvolvidas para essa área.

Apesar disso, (e mesmo ainda carecendo de regulamentação), a Lei $\mathrm{n}^{\circ} 19.307$ traz um avanço fundamental para o debate uruguaio, e de toda a região sobre um modelo de mídia mais democrático, já que o texto reflete muitas das recomendações realizadas pela sociedade civil.

Desde que foi aprovada, a nova lei recebe fortes rechaços por parte da oposição e do empresariado das comunicações uruguaio. Essa frente, juntamente com o Partido Independente, acusa diversos artigos da lei de inconstitucionailidade. Seus argumentos são de que a lei viola a liberdade de expressão, o direito de propriedade e a "liberdade de empreendimento". Questionam também o capítulo sobre publicidade eleitoral gratuita, alegando conflito com as normais eleitorais existentes no país e a transmissão gratuita de eventos considerados de interesse público, como partidas esportivas. A empresa DirecTV 
também contesta judicialmente 27 artigos da nova lei, acusando-os de limitadores do mercado e da liberdade de expressão. Quando se pronunciou sobre o tema, o fiscal da Corte uruguaia, Jorge Díaz, opinou que considera cinco artigos inconstitucionais e que outros nove apresentam problemas de constitucionalidade, sem no entanto defini-los (VÁZQUEZ DA LA DERECHA, 2015). Até o fechamento deste texto, em fevereiro de 2016, a nova lei de meios uruguaia ainda não havia sido regulamentada, segundo o presidente Tabaré Vázquez, por estar aguardando o julgamento da Suprema Corte de Justiça (SCJ) em relação a essas acusações de inconstitucionalidade de alguns de seus artigos.

\section{Agradecimentos e Observações}

Versão revisada e atualizada de texto apresentado ao Grupo de Trabalho Políticas de Comunicação do VI Congresso da Associação Brasileira de Pesquisadores em Comunicação e Política (VI Compolítica), na Puc-Rio, de 22 a 24 de abril de 2015.

\section{Notas}

1 TORQUATO, 2014.

2 TORQUATO, 2014.

${ }^{3}$ Entrevista concedida por Gabriel Kaplún à pesquisadora em 3 de julho de 2013 em Montevidéu. Tradução livre.

4 "El espectro radioeléctrico es un patrimonio común de la humanidad sujeto a administración de los Estados y, por tanto, el acceso equitativo a las frecuencias de toda la sociedad uruguaya constituye un principio general de su administración"

5 "Se entiende por SCA un servicio cuya principal finalidad es proporcionar programas con objeto de informar, entretener o educar, a través de redes de comunicaciones electrónicas, de televisión o radiodifusión sonora por medio de una oferta estable y permanente de contenidos, sobre la base de un horario de programación". Tradução livre.

6 "Me tienen podrido con esa pregunta (en referencia a la futura Ley de Servicios de Comunicación Audiovisual). ¡Podrido! Al gobierno no le han traído nada, pero cuando lo hagan la voy a tirar a la papelera". Tradução livre.

7 TORQUATO, 2014.

${ }^{8}$ Eles não podem ocupar cargos públicos dentro de um prazo de três anos após data de rescisão, assim como não podem ter vínculos com emissoras, partidos políticos ou outro emprego remunerado que não seja atividade acadêmica.

${ }^{9}$ No que se refere à direção do SPRTN, ela deve ser exercida por um presidente, um vicepresidente e um porta-voz designados pelo Executivo, tendo seu mandado a ele vinculado. Esse diretório irá designar a direção da Rádio Nacional e da TV Nacional (URUGUAY, 2015).

${ }^{10}$ Esses precisam ter ao menos $80 \%$ de conteúdo nacional e ser selecionados a cada cinco anos mediante concurso público e transparente, com audiência pública (URUGUAY, 2015).

${ }^{11}$ No capítulo da lei relativo aos direitos dos prestadores de SCA estão, principalmente, o reforço à independência, liberdade editorial, de lucrar com publicidade, deter exclusividade de conteúdos audiovisuais (desde que não sejam de interesse geral), compartilhar canais e oferecer serviços 
interativos. Já no capítulo referente aos jornalistas, atrelam-se suas atividades ao disposto na lei de imprensa 16.099 de 1989 e a lei 18.515, de 2009. Além disso, é estabelecido que eles possuem o direito de negar-se a atrelar sua imagem, voz ou nome a conteúdos de sua autoria que tenham sido modificados sem seu consentimento (URUGUAY, 2015).

${ }^{12}$ TORQUATO, 2014.

\section{Referências}

AMARC ALC - ASOCIACIÓN MUNDIAL DE RADIOS COMUNITARIAS - AMERICA LATINA E CARIBE. Informe anual: diversidad y pluralismo en la radiodifusión. Buenos Aires, 2010.

ARAÚJO, A.; OLIVEIRA, T. A comunicação pública do Uruguai: tropeços e andanças em direção à cidadania. In: IPEA - INSTITUTO DE PESQUISA ECONÔMICA E APLICADA. Panorama da comunicação e das telecomunicações no Brasil. 2012/2013. Indicadores e tendências. Brasília, 2013.

LANZA, E. Caracterización de las contradicciones y obstáculos de la construcción de una regulación democrática para los servicios audiovisuales en Uruguay. In: CONGRESO LATINOAMERICANO DE INVESTIGADORES DE LA COMUNICACIÓN, 11., 2012. Montevideo. Anais. Montevideo: ALAIC, 2012.

; BUQUET, G. La televisión privada comercial en Uruguay: caracterización de la concentración de la propiedad, das audiencias y la facturación. In: Análisis e propuestas. Montevideo: Fundación Friedrich Ebert, 2011.

.; GOLDARACENA, O. Uruguay. In: AMARC - ASOSIACIÓN MUNDIAL DE RADIOS COMUNITÁRIAS. Las Mordazas invisibles: nuevas y viejas barreras a la diversidad en la radiodifusión. Programa de legislaciones y derecho a la comunicación. Buenos Aires, 2009. p. 229-248

MENEZES, M.; AGUM, R. Regulação dos serviços de telecomunicações e comunicação no Cone Sul: uma análise comparada entre: Argentina Brasil, Chile, Uruguai e Paraguai. In: LIMA, J.C.G.; MELO, J.M. (Org.). Panorama da comunicação e das telecomunicações no Brasil: 2012/2013. Brasília: Ipea, 2013. v. 2, p. 157-213.

RUBIO, C. G. Lo que el cable nos dejó: televisión para abonados, comunicación y democracia en Uruguay. Montevideo: La Pluma, 1994.

SI ME TRAEN una ley de medios va a la papelera. El Pais. 07 dez. 2010. Disponível em: <http://historico.elpais.com.uy/101206/pnacio-533496/politica/-si-me-traen-una-ley-de-mediosva-a-la-papelera-/> Acesso em: 19 set. 2013.

TORQUATO, Chalini. Democratização da comunicação: discussão teórico-conceitual e análise comparada de ambientes regulatórios para o setor de televisão nos países do MERCOSUL. 2014. 390 f. Tese. (Doutorado em Comunicação). Programa de Pós-Graduação em Comunicação e Cultura Contemporâneas da Universidade Federal da Bahia. Disponível em: < http://poscom.tempsite.ws/wp-content/uploads/2011/05/Chalini-Torquato-Gonçalves-de-

Barros.pdf> . Acesso em 29 set 2016. 
URUGUAY. Ley n. 18.232. Servicio de Radiodifusión Comunitaria. 9 enero 2008. Disponível em: <http://200.40.229.134/leyes/AccesoTextoLey.asp?Ley=18232> Acesso em: 19 out. 2013.

URUGUAY. Ley n. 19.307. 14 enero 2015. Disponível em: <www.impo.com.uy/bases/leyes/19307-2014>. Acesso em: 23 mar 2015.

VÁZQUEZ DA LA DERECHA a la Corte con Ley de Medios. El Observador. 28 jun 2015. Disponível em: <http://www.elobservador.com.uy/vazquez-da-la-derecha-la-corte-ley-mediosn656297>.

\section{A autora}

Chalini Torquato Gonçalves Barros é professora adjunta da Escola de Comunicação/UFRJ e doutora em Comunicação pelo PósCom/UFBA. chalini.torquato@eco.ufrj.br 